\title{
A study of antioxidant activity, enzymatic inhibition and in vitro toxicity of selected traditional sudanese plants with anti-diabetic potential
}

\author{
Yasmin Hilmi ${ }^{1 *}$, Muna F Abushama' ${ }^{1}$, Haidar Abdalgadir ${ }^{2}$, Asaad Khalid ${ }^{2}$ and Hassan Khalid ${ }^{1}$
}

\begin{abstract}
Background: Diabetes mellitus is a chronic metabolic disease with life-threatening complications. Despite the enormous progress in conventional medicine and pharmaceutical industry, herbal-based medicines are still a common practice for the treatment of diabetes. This study evaluated ethanolic and aqueous extracts of selected Sudanese plants that are traditionally used to treat diabetes.

Methods: Extraction was carried out according to method described by Sukhdev et. al. and the extracts were tested for their glycogen phosphorylase inhibition, Brine shrimp lethality and antioxidant activity using (DPPH) radical scavenging activity and iron chelating activity. Extracts prepared from the leaves of Ambrosia maritima, fruits of Foeniculum vulgare and Ammi visnaga, exudates of Acacia Senegal, and seeds of Sesamum indicum and Nigella sativa.

Results: Nigella sativa ethanolic extract showed no toxicity on Brine shrimp Lethality Test, while its aqueous extract was toxic. All other extracts were highly toxic and ethanolic extracts of Foeniculum vulgare exhibited the highest toxicity. All plant extracts with exception of Acacia senegal revealed significant antioxidant activity in DPPH free radical scavenging assay.

Conclusions: These results highly agree with the ethnobotanical uses of these plants as antidiabetic. This study endorses further studies on plants investigated, to determine their potential for type 2 diabetes management. Moreover isolation and identification of active compounds are highly recommended.
\end{abstract}

Keywords: Diabetes mellitus, Medicinal plants, Antioxidant activity, Glycogen phosphorylase, Brine shrimp

\section{Background}

Diabetes mellitus (DM) is a disease with severe complications and major health/economic impacts. It is a leading cause of morbidity and mortality worldwide, with an estimated 346 million adults being affected in year 2011 . WHO projects that diabetes death will increase by twothirds between 2008 and 2030 [1]. The prevalence of diabetes for all age-groups worldwide was estimated to be $2.8 \%$ in 2000 and $4.4 \%$ in 2030 [2].

In Sudan diabetes is an increasingly important problem, being responsible for $10 \%$ of hospital admissions and mortality [3]. Recently, an increase in incidence of DM has been observed especially among urbanized population indicating that diabetes mellitus is emerging as an

\footnotetext{
* Correspondence: yasminabusamra@hotmail.com

'Khartoum College of Medical Sciences, P.O Box 10995, Khartoum, Sudan

Full list of author information is available at the end of the article
}

important health problem [4]. The results of a smallscale study carried out in 1996 indicated that diabetes population in Sudan is at around one million, 90\% of them have type 2 diabetes. It also showed a prevalence of $3.4 \%$ of type 2 DM [5].

Nature is an extraordinary source of medicines. The use of traditional medicines and medicinal plants in most developing countries as therapeutic agents for the maintenance of good health has been widely observed. The World Health Organization estimated that $80 \%$ of the populations of developing countries rely on traditional medicines, mostly plant drugs, for their primary health care needs. Diabetes is an example of a disease that has been treated with plant medicines. Research conducted in the last few decades on plants used traditionally for treatment of diabetes has shown antidiabetic properties [6]. 
To date, more than 1200 flowering plants have been claimed to have antidiabetic properties. Among them, only one-third have been scientifically studied and documented in around 460 publications [7].

The Sudanese flora has a vast variety of medicinal plants, which are traditionally used for their antidiabetic property. However, careful assessment including sustainability of such herbs, seasonal variation in activity of phyto-constituents, metal contents of crude herbal antidiabetic drugs, thorough toxicity study and cost effectiveness is required for their popularity. These efforts may justify the role of novel traditional medicinal plants having anti-diabetic potentials.

Herbal drugs are considered free from side effects than synthetic one. They are less toxic, relatively cheap and popular [8]. However cytotoxicity of these plants needs to be monitored.

Brine shrimp bioassays (BSLT) offer a quick, simple and cost-efficient way of testing the toxicity of plant extracts. It has been developed for screening, fractionation and monitoring of biologically active natural products $[9,10]$.

Oxidative stress has been implicated in the development of many pathophysiological conditions including diabetes. Oxidative stress takes place due to the disturbance of the balance between the formation of reactive oxygen species (ROS) and the defense provided by cellular antioxidants. Medicinal plants provide a natural source of antioxidants that have been used worldwide for treatment of many diseases [6].

The inhibition of glycogen phosphorylase has been used as one method for treating type 2 diabetes. Since glucose production in the liver has been shown to increase in type 2 diabetes patients, inhibiting the release of glucose from the liver's glycogen's supplies appears to be a valid approach $[11,12]$.

In the present study we assessed the antioxidant and hypoglycemic activities of ethanolic and aqueous extracts of Ambrosia maritima, Ammi visnaga, Acacia senegal, Sesamum indicum, Nigella sativa, Foeniculum vulgare of Sudanese origin. Screening of toxicity of these plants using brine shrimp lethality test, is also investigated.

\section{Methods}

\section{Plant Material}

Plants collected from Khartoum local market, identified and authenticated by Dr. Haider Abdelgadir, Herbarium Curator. Herbarium material was deposited at The Medicinal \& Aromatic Plants Research Institute (MAPRI), Khartoum, Sudan. Table 1 shows the tested plants, their parts used and medicinal uses.

\section{Preparation of plant extracts}

Extraction was carried out according to method described by Sukhdev et. al. [13].

\section{Preparation of ethanolic extract}

Specific weight of each plant sample was extracted by soaking in $96 \%$ ethanol for about seventy two hours with daily filtration and evaporation. Solvent was evaporated under reduced pressure to dryness using rotary evaporator apparatus and the extract combined together. The yield percentage was calculated as followed:

$$
\text { Weight of extract/weight of sample } \times 100
$$

\section{Preparation of the aqueous extract}

About 50-100 g of each plant sample was soaked in $500 \mathrm{ml}$ hot distilled water, and left till cooled down with continuous stirring at room temperature. Extract was then filtered and freeze dried. Yield percentage was calculated.

Weight of extract obtained/weight of plant sample $\times 100$

\section{Brine Shrimp Lethality Test}

Artemia salina (shrimp eggs) was placed in natural sea water, and eggs hatched within 48 hrs, providing a large number of larvae (nauplii). The tested sample $(20 \mathrm{mg}$ ) was dissolved in $2 \mathrm{ml}$ of ethanol. From this solution 5, 50 and $500 \mu \mathrm{l}$ were transferred to vials (triplicate for each concentration), forming concentrations of 10, 100 and $1000 \mu \mathrm{g} / \mathrm{ml}$ respectively. The solvent was allowed to evaporate overnight. Volume was made to $5 \mathrm{ml}$ with seawater. 10 larvae were placed in each vial using a Pasteur pipette. Vials were incubated at $25-27^{\circ} \mathrm{C}$ for $24 \mathrm{hrs}$ under illumination. Etoposide $(7.4625 \mu \mathrm{g} / \mathrm{ml})$ was used as positive control, and number of survived larvae were counted. Data was analyzed by Finney Probit Analysis computer program to determine $\mathrm{LC}_{50}$ values with $95 \%$ confidence intervals [9].

\section{Antioxidant activity assays}

1. DPPH radical scavenging assay

The DPPH radical scavenging was determined according to the modified method of Shimada et al. [14] in 96-wells plate, the test samples were allowed to react with 1,1-Diphenyl-2-picryl-hydrazyl stable free radical $(\mathrm{DPPH})$ for half an hour at $37^{\circ} \mathrm{C}$. The concentration of DPPH was kept as $300 \mu \mathrm{M}$. The test samples were dissolved in DMSO while DPPH was prepared in ethanol. After incubation, decrease in absorbance was measured at $517 \mathrm{~nm}$ using multiple reader spectrophotometer. Percentage radical scavenging activity by samples was determined in comparison with a DMSO treated control group. All tests and analysis were run in triplicate. Vitamin $\mathrm{C}$ was used as positive control

2. Iron chelating activity assay The iron chelating ability was determined according to the modified method of Dinis et al. [15]. The Fe $\mathrm{Fe}^{+2}$ 
Table 1 Tested plants

\begin{tabular}{|c|c|c|c|}
\hline Plant name & Family & Parts used & Reported medicinal uses [17-20] \\
\hline Acacia senegal & Fabaceae-Mimosoidae & Fruits & $\begin{array}{l}\text { Treatment of diabetes and chronic renal failure. Stem exudates (gums) } \\
\text { are used as demulcents and against diarrhoea and ulcers }\end{array}$ \\
\hline Ambrosia maritima & Asteraceae & Leaves & $\begin{array}{l}\text { Hepatoprotective and Molluscicidal, The herbs are used in treatment of } \\
\text { urinary tract infections and elimination of kidneystones, whereas the } \\
\text { leaves are used as anti-diabetic and anti-hypertensive }\end{array}$ \\
\hline Ammi visnaga & Apiaceae & Fruits & Used for renal urethra stones, smooth muscle relaxant \\
\hline Foeniculum vulgare & Apiaceae & Fruits & Carminative, flatulence and digestive. It is also used in veterinary medicine \\
\hline Nigella sativa & Ranunculaceae & Seeds & $\begin{array}{l}\text { Treatment of diabetes, hypertension, abdominal ulcers, prostate gland and } \\
\text { lung injury(Cuneyt Tayman) }\end{array}$ \\
\hline Sesamum indicum & Pedaliaceae & Seeds & $\begin{array}{l}\text { Treatment, for cough and cold. also used as nutritive, laxative, demulcent } \\
\text { and emollient propertie }\end{array}$ \\
\hline
\end{tabular}

were monitored by measuring the formation of ferrous ion-ferrozine complex. The experiment was carried out in 96 microtiter plate. The plant extracts were mixed with $\mathrm{FeSO}_{4}$. The reaction was initiated by adding $5 \mathrm{mM}$ ferrozine. The mixture was shaken and left at room temperature for $10 \mathrm{~min}$. The absorbance was measured at $562 \mathrm{~nm}$. EDTA was used as standard, and DMSO as control. All tests and analysis were run in triplicate.

\section{Glycogen phosphorylase enzyme assays}

Glycogen phosphorylase a (from rabbit muscle), glycogen, glucose-1-phosphate, malachite green, and ammonium molybdate were purchased from the Sigma-Aldrich Corporation. Reagents and solvents were obtained from commercial suppliers and used without further purification. Solvents used were AR grade. The enzymatic inhibition of phosphorylase activity was monitored using multiskan spectrum (Thermo-Scientific) based on the published methods. In brief, GPa activity was measured in the direction of glycogen synthesis by the release of phosphate from glucose-1-phosphate. Each compound was dissolved in DMSO and diluted at different concentrations for IC50 determination. The enzyme was added into the $100 \mu \mathrm{L}$ buffer with compounds dissolved in containing $50 \mathrm{mM}$ Hepes ( $\mathrm{pH}$ 7.2), $100 \mathrm{mM} \mathrm{KCl,} 2.5 \mathrm{mM} \mathrm{MgCl} 2,0.5 \mathrm{mM}$ glucose-1-phosphate, and $1 \mathrm{mg} / \mathrm{mL}$ glycogen in 96-well microplates (costar). After the addition of $150 \mu \mathrm{L}$ of $1 \mathrm{M}$ $\mathrm{HCl}$ containing $10 \mathrm{mg} / \mathrm{mL}$ ammonium molybdate and $0.38 \mathrm{mg} / \mathrm{mL}$ malachite green, reactions were run at $25^{\circ} \mathrm{C}$ for $20 \mathrm{~min}$. And then the phosphate absorbance was measured at $620 \mathrm{~nm}$ [16].

\section{Results and discussion}

Different medicinal systems that have been discovered as natural hypoglycemic medicine came from the virtue of traditional knowledge and have been used in many countries [7,21,22].

Many herbal extracts are currently traditionally used in Sudan for the treatment of diabetes. However, such medicinal plants have not gained much importance as medicines due to the lack of sustained scientific evidence. In the present study, aqueous and ethanolic extracts of six indigenous antidiabetic medicinal plants from Sudan were studied. The rationale for performing extractions from polar to non-polar solvents is to confirm and validate the inhibitory activity in the aqueous extractions performed in the traditional manner as well as to search for newer, more potent inhibitory compounds in the organic solvents. Since the Sudanese population has long been using all these plants for food and medicinal purposes, they form a part of the local pharmacopoeia.

Increasing evidence in both experimental and clinical studies suggests that oxidative stress plays a major role in the pathogenesis of both types of DM. Free radicals are formed disproportionately in diabetes by glucose oxidation, nonenzymatic glycation of proteins, and the subsequent oxidative degradation of glycated proteins. Abnormally high levels of free radicals and the simultaneous decline of antioxidant defense mechanisms can lead to damage of cellular organelles and enzymes, increased lipid peroxidation, and development of insulin resistance. These consequences of oxidative stress can promote the development of complications of DM. Changes in oxidative stress biomarkers, and use of antioxidants is an important trend in the treatment of DM [23].

In the present work we studied the anti-oxidant activity of ethanolic and aqueous extracts of investigated plants. Samples will be considered to have high or significant antioxidant capacity with IC50<50 $\mu \mathrm{g} / \mathrm{ml}$ (extract) or IC50 $<10 \mu \mathrm{g} / \mathrm{ml}$ (compounds), moderate antioxidant capacity with $50<\mathrm{IC} 50<100 \mu \mathrm{g} / \mathrm{ml}$ (extract) or $10<$ IC50 $<20 \mu \mathrm{g} / \mathrm{ml}$ (compounds) and low antioxidant capacity with IC50 $>100 \mu \mathrm{g} / \mathrm{ml}$ (extract) or IC50 $>20 \mu \mathrm{g} / \mathrm{ml}$ (compounds) [24]. Ambrosia maritima, Ammi visnaga and Foeniculum vulgare exhibited high antioxidant activity in DPPH free radical scavenging assay with IC50 of $36 \mu \mathrm{g} /$ $\mathrm{ml}$ of ethanol extract of Ambrosia maritima, $41 \mu \mathrm{g} / \mathrm{ml}$ of ethanol extract of Ammi visnaga, $47 \mu \mathrm{g} / \mathrm{ml}$ of aqueous extract of Ammi visnaga, $49 \mu \mathrm{g} / \mathrm{ml}$ of ethanol extract of 
Foeniculum vulgare and $31 \mu \mathrm{g} / \mathrm{ml}$ of aqueous extract of Foeniculum vulgare. This may support the traditional usage of these plants to improve complications such oxidative stress that caused by DM as well as many other diseases. A study in Egypt by Abu Zid and coworkers showed a moderate antioxidant activity of aqueous extract of M. ambrosia [25]. Results of Achyranthes aspera extracts in alloxan-treated mice revealed significant antihyperglycemic activity that may be mediated by diminished oxidative stress [26]. A study of Eucalyptus globulus, Salvia officinalis growing in Algeria and Guiera senegalensis growing in Sudan demonstrated that the $96 \%$ alcoholic leaf extracts had a significant blood-glucose lowering potential in glucose loaded rats with minimum toxicity [27]. Swanston and coworkers reported that agrimony, alfalfa, coriander, eucalyptus and juniper, can retard the development of streptozotocin diabetes in mice [28]. In another study, ethanolic crude extract of Sorbus decora demonstrates both anti-hyperglycemic and insulin-sensitizing activity in vivo, thereby confirming anti-diabetic potential and validating traditional medicine [29]. Trigonella foenumgraecum, Atriplex halimus, Olea europaea, Urtica dioica, Allium sativum, Allium cepa, Nigella sativa, and Cinnamomum cassia were tested for their antidiabetic properties. Results indicated that the observed anti-diabetic properties of these plants are mediated, at least partially, through regulating GLUT4 translocation [30].

Glycogen phosphorylase inhibition has been used as one method for treating type 2 diabetes [11,12]. Results of the current study did not show any significant inhibition of glycogen phosphorylase, but extracts of these plants may act on one of other enzymatic reactions that are involved in carbohydrate metabolism and improved glucose homeostasis.

All aqueous extracts showed significantly high toxicity on Brine shrimp Lethality Test, while Foeniculum vulgare showed moderate toxicity. Ethanolic extract of Nigella sativa showed no toxicity while all other ethanolic extracts exhibited high toxicity. Ethanolic extracts of Foeniculum vulgare exhibited the highest toxicity. These statistical consideration are based on the published work by Bussmann and coworkers. They stated that $\mathrm{LC}_{50}$ values below $249 \mu \mathrm{g} / \mathrm{ml}$ are considered as highly toxic, 250$499 \mu \mathrm{g} / \mathrm{ml}$ as median toxicity and $500-1000 \mu \mathrm{g} / \mathrm{ml}$ as light toxicity. Values above $1000 \mu \mathrm{g} / \mathrm{ml}$ are regarded as non-toxic [31]. These results could be very useful as preliminary data in the search for new antitumor compounds from the Sudanese market flora. All results for antioxidant activities, glycogen phosphorylase inhibition and cytotoxicity are shown in Table 2.

\section{Conclusions}

In conclusion these results revealed the significant antioxidant activity of the investigated plants extracts and may explain their role in altering the oxidative stress and management of diabetes mellitus. Furthermore the high toxicity of many extracts tested in this study suggests their antitumor potential and provides an avenue to explore the bioactive components of plant extracts. Studies should be directed towards drug industry by identification of single chemical compounds, and dosage use has to be monitored.

\section{Recommendations}

1. In an effort to expand treatment options, there is a need to continue exploring the relationship between free radicals, diabetes, and its complications, and to elucidate the mechanisms by which increased oxidative stress accelerates the development of diabetic complications.

Table 2 Antioxidant activity, enzymatic inhibition and cytotoxicity of selected Sudanese medicinal plants

\begin{tabular}{|c|c|c|c|c|c|}
\hline Plant & Extract & $\begin{array}{l}\text { DPPH radical } \\
\text { scavenging assay } \%\end{array}$ & $\begin{array}{l}\text { Iron chelating } \\
\text { assay } \%\end{array}$ & $\begin{array}{l}\text { Inhibition \% of glycogen } \\
\text { phosphorylase }(5 \mathrm{mg} / \mathrm{ml})\end{array}$ & $\begin{array}{l}\text { Brine shrimp } \\
\left.\text { lethality (LC }{ }_{50}\right)\end{array}$ \\
\hline \multirow[t]{2}{*}{ Acacia Senegal } & Ethanolic & NOT ACTIVE & NOT ACTIVE & 0 & 83.8716 \\
\hline & Aqueous & NOT ACTIVE & NOT ACTIVE & 0 & 17.9948 \\
\hline \multirow[t]{2}{*}{ Ambrosia maritima } & Ethanolic & $60.8 \pm 0.04$ & NOT ACTIVE & 2.2 & 39.7866 \\
\hline & Aqueous & $21.2 \pm 0.02$ & NOT ACTIVE & 0 & 10.6353 \\
\hline \multirow[t]{2}{*}{ Ammi visnaga } & Ethanolic & $52.4 \pm 0.03$ & NOT ACTIVE & 0 & 8.1217 \\
\hline & Aqueous & $52.4 \pm 0.03$ & $2.5 \pm 0.03$ & 0 & 32.6273 \\
\hline \multirow[t]{2}{*}{ Foeniculum vulgare } & Ethanolic & $60.7 \pm 0.06$ & $3.6 \pm 0.05$ & 0 & 0.012 \\
\hline & Aqueous & $69.4 \pm 0.003$ & NOT ACTIVE & 0 & 893.97 \\
\hline \multirow[t]{2}{*}{ Nigella sativa } & Ethanolic & $47 \pm 0.02$ & $6.3 \pm 0.02$ & 0 & 11684.6 \\
\hline & Aqueous & $19.3 \pm 0.01$ & $43.5 \pm 0.04$ & 0 & 122.268 \\
\hline \multirow[t]{2}{*}{ Sesamum indicum } & Ethanolic & NOT ACTIVE & NOT ACTIVE & 8.2 & 61.85 \\
\hline & Aqueous & $40.3 \pm 0.01$ & $23.2 \pm 0.02$ & 0 & 1.7 \\
\hline
\end{tabular}


2. Further research into the pathophysiology of oxidative stress and the role of antioxidant therapy will lead to appropriately-designed clinical trials in which the promise of antioxidant therapy will be realized. In addition, further investigations for isolation and identification of active compounds are highly recommended.

3. Extraction processes and usage doses should be monitored. Necessary precautions should be taken while supplementing these extracts in order to avoid other complications of toxicity.

\section{Competing interest}

We declare that we have no competing interests, financially or otherwise.

\section{Authors' contributions}

$\mathrm{YH}$ participated in the study design and coordination, carried out the toxicity assay, drafted the manuscript and rewrote the final one. MA participated in the design of the study, toxicity assay and helped to draft the manuscript. HA conceived of the study, and participated in its design and coordination. AK participated in the enzymatic inhibition study and antioxidant activity. HK supervised part of the study and reviewed the manuscript. All authors read and approved the final manuscript.

\section{Acknowledgement}

The authors are grateful to the Medicinal \& Aromatic Plants Research Centre (Khartoum, Sudan) for providing necessary laboratory facilities. We thank Mr. Muddathir Alhassan for his technical contribution in extraction methods. We thank Ms. Fatima Elfatih for her technical assistance in the enzymatic inhibition assays and Mr. Eltayeb Fadul for carrying out the IC50 analysis.

\section{Author details}

${ }^{1}$ Khartoum College of Medical Sciences, P.O Box 10995, Khartoum, Sudan. ${ }^{2}$ Medicinal and Aromatic Plants Research Institute, National Centre for Research, P.O.Box 2420 Khartoum, Sudan.

Received: 15 December 2013 Accepted: 29 April 2014 Published: 7 May 2014

\section{References}

1. WHO Diabetes Fact Sheet No312 September (2012). http://www.who.int/ mediacentre/factsheets/fs312/en/index.html.

2. Wild S, Bchir M, Roglic G, Green A, Sicree R, King H: Global Prevalence of Diabetes Estimates for the year 2000 and projections for 2030. Diabetes Care 2004, 27:1047-1053.

3. Ahmed AM, Ahmed NH, Abdalla ME: Pattern of hospital mortality among diabetic patients in Sudan. Pract Diabetes Int 2000, 17:41-43.

4. Ahmed AM: Diabetes mellitus in Sudan: size of the problem and possibilities of efficient care. Pract Diabetes Int 2001, 18:324-327.

5. Elbagir MN, Eltom MA, Elmahadi EM, Kadam IM, Berne C: A population-based study of the prevalence of diabetes and impaired glucose tolerance in adults in northern Sudan. Diabetes Care 1996, 19(10):1126-1128.

6. Abou El-Soud N, El-Laithy N, El-Saeed G, Wahby M, Khalil M, Morsy F, Shaffie N: Antidiabetic Activities of Foeniculum Vulgare Mill. Essential Oil in Streptozotocin-Induced Diabetic Rats. Macedonian J Med Sci 2011, 4(2):139-146.

7. Chang CL, Lin Y, Bartolome AB, Chen YC, Chiu SC, Yang WC: Herbal Therapies for Type 2 Diabetes Mellitus:Chemistry, Biology, and Potential Application of Selected Plants and Compounds. Evidence-Based Complement Altern Med 2013, 33. Article ID 378657. http://dx.doi.org/ 10.1155/2013/378657.

8. Gupta R, Bajpai KG, Johri S, Saxena AM: An overview of Indian novel traditional medicinal plants with antidiabetic potentials. Afr J Trad CAM 2008, 5(1):1-17.

9. McLaughlin JL, Rogers LL, Anderson JE: The Use of Biological Assays to Evaluate Botanicals. Drug Inf J 1998, 32:513-524.

10. Bastos MLA, Lima MRF, Conserva LM, Andrade VS, Rocha EMM, Lemos RPL: Studies On The Antimicrobial Activity And Brine Shrimp Toxicity Of Zeyheria tuberculosa (Vell.) Bur. (Bignoniceace) Extracts And Their Main Constituents. Ann Clin Microbiol Antimicrob 2009, 8:16-20.
11. Somsák L, Nagya V, Hadady Z, Docsa T, Gergely P: Glucose analog inhibitors of glycogen phosphorylases as potential antidiabetic agents: recent developments. Current Pharmacological Design 2003, 9(15):1177-1189.

12. Moller DE: New drug targets for type 2 diabetes and the metabolic syndrome. Nature 2001, 414(6865):821-827.

13. Sukhdev SH, Suman PSK, Gennaro L, Dev DR: Extraction technologies for medicinal and aromatic plants. In, Chapter 1. United Nations Industrial Development Organization and the International Centre for Science and High Technology, Italy. ; 2008

14. Shimada K, Fujikawa K, Yahara K, Nakamura T: Antioxidative properties of xanthan on the antioxidation of soybean oil in cyclodextrin emulsion. J Agric Food Chem 1992, 40(6):945-948.

15. Dinis TCP, Madeira VMC, Almeida LM: Action of phenolic derivates (acetoaminophen, salycilate and 5-aminosalycilate) as inhibitor of membrane lipid peroxidation and as peroxyl radical scavengers. Arch Biochem Biophys 1994, 315:161-169.

16. Martin WH, Hoover DJ: Discovery of a human liver glycogen phosphorylase inhibitor that lowers blood glucose in vivo. Proc Natl Acad Sci U S A 1998, 95(4):1776-1781.

17. Khalid H, Abdella W, Abdelgadir H, Opatz T, Efferth T: Gems from traditional north-African medicine: medicinal and aromatic plants from Sudan Nat. Prod Bioprospect 2012, 2:92-103.

18. Vanachayangkul P, Chow N, Khan SR, Butterweck V: Prevention of renal crystal deposition by an extract of Ammi visnaga $\mathrm{L}$. and its constituents khellin and visnagin in hyperoxaluric rats. Urol Res 2011, 39(3):189-195.

19. Ghanem MTM, Radwan HMA, Mahdy EM, Elkholy YM, Hassanein HD, Shahat AA: Phenolic compounds from Foeniculum vulgare (Subsp. Piperitum) (Apiaceae) herb and evaluation of hepatoprotective antioxidant activity. Pharmacognosy Res 2012, 4(2):104-108.

20. Tayman C, Cekmez F, Kafa I, Canpolat F, Cetinkaya M, Tonbul A, Uysal S, Tunc T, Sarici S: Protective Effects of Nigella sativa Oil in Hyperoxia-Induced Lung Injury. Arch Bronconeumol 2013, 49(1):15-21.

21. Baldé NM, Youla A, Baldé MD, Kaké A, Diallo MM, Baldé MA, Maugendre D: Herbal medicine and treatment of diabetes in Africa : an example from Guinea. Diabetes Metab 2006, 32(2):171-175.

22. Singh S, Gupta S, Sabir G, Gupta M, Seth P: Database for anti-diabetic plants with clinical/experimental trials. Bioinformation 2009, 4(6):263-268.

23. Maritim AC, Sanders RA, Watkins JB 3rd: Diabetes, oxidative stress, and antioxidants: a review. J Biochem Mol Toxicol 2003, 17(1):24-38.

24. Kuete $\mathrm{V}$, Efferth $\mathrm{T}$ : Cameroonian medicinal plants: pharmacology and derived natural products. Front Pharmacol 2010, 1:123.

25. AbouZid S, Elshahaat A, Ali S, Choudhary M: Antioxidant activity of wild plants collected in Beni-Sueif. Upper Egypt. Drug Discov Ther 2008, 2(5):286-288.

26. Talukder F, Khan K, Uddin R, Jahan N, Alam A: In vitro free radical scavenging and anti-hyperglycemic activities of Achyranthes aspera extract in alloxaninduced diabetic mice. Drug Discoveries Therapeut 2012, 6(6):298-305.

27. Houacine $\mathrm{CH}$, Elkhawad AO, Ayoub SMH: A comparative study on the anti-diabetic activity of extracts of some Algerian and Sudanese plants. $J$ Diabet Endocrin 2012, 3(3):25-28.

28. Swanston-Flatt SK, Day C, Bailey CJ, Flatt PR: Traditional plant treatments for diabetes. Studies in normal and streptozotocin diabetic mice. Diabetologia 1990, 33(8):462-464.

29. Vianna R, Brault A, Martineau LC, Couture R, Arnason JT, Haddad PS: In Vivo Anti-Diabetic Activity of the Ethanolic Crude Extract of Sorbus decora C.K. Schneid. (Rosacea): A Medicinal Plant Used by Canadian James Bay Cree Nations to Treat Symptoms Related to Diabetes. Evidence-Based Complement Altern Med 2011, 7. Article ID 237941 10.1093/ecam/nep158.

30. Kadan S, Saad B, Sasson Y, Zaid H: In Vitro Evaluations of Cytotoxicity of Eight antidiabetic Medicinal Plants and Their Effect on GLUT4 Translocation. Evidence-Based Complement Altern Med 2013, 9. Article ID 549345 http://dx.doi. org/10.1155/2013/549345.

31. Bussmann R, Malca G, Glenn A, Sharon D, Nilsen B, Parris B, Dubose D, Ruiz D, Saleda A, Martinez M, Carillo L, Walker K, Kuhlman A, Townesmith A: Toxicity of medicinal plants used in traditional medicine in Northern Peru. J Ethnopharmacol 2011, 137(1):121

\section{doi:10.1186/1472-6882-14-149}

Cite this article as: Hilmi et al:: A study of antioxidant activity, enzymatic inhibition and in vitro toxicity of selected traditional sudanese plants with anti-diabetic potential. BMC Complementary and Alternative Medicine 2014 14:149. 